Article

\title{
Fluorine-Containing Dibenzoanthracene and Benzoperylene-Type Polycyclic Aromatic Hydrocarbons: Synthesis, Structure, and Basic Chemical Properties
}

\author{
Otohiro Gotsu ${ }^{1}$, Tomomi Shiota ${ }^{1}$, Hiroki Fukumoto ${ }^{1, *(1)}$, Tomoko Kawasaki-Takasuka ${ }^{2}$, \\ Takashi Yamazaki ${ }^{2}$, Tomoko Yajima ${ }^{3}$, Tomohiro Agou ${ }^{1, *(D)}$ and Toshio Kubota ${ }^{1, *}$ \\ 1 Department of Quantum Beam Science, Graduate School of Science and Engineering, Ibaraki University, \\ 4-12-1 Nakanarusawa, Hitachi, Ibaraki 316-8511, Japan; 16nd105r@vc.ibaraki.ac.jp (O.G.); \\ tomo.514a@gmail.com (T.S.) \\ 2 Division of Applied Chemistry, Institute of Engineering, Tokyo University of Agriculture and Technology, \\ 2-24-16 Nakamachi, Koganei, Tokyo 184-8588, Japan; takasuka@cc.tuat.ac.jp (T.K.-T.); \\ tyamazak@cc.tuat.ac.jp (T.Y.) \\ 3 Department of Chemistry, Faculty of Science, Ochanomizu University, Otsuka, Bunkyo-ku, Tokyo 112-8610, \\ Japan; yajima.tomoko@ocha.ac.jp \\ * Correspondence: hiroki.fukumoto.chem@vc.ibaraki.ac.jp (H.F.); \\ tomohiro.agou.mountain@vc.ibaraki.ac.jp (T.A.); toshio.kubota.organicchem@vc.ibaraki.ac.jp (T.K.); \\ Tel.: +81-294-38-5071 (H.F.)
}

Academic Editor: Pierre-Antoine Bouit

Received: 20 November 2018; Accepted: 11 December 2018; Published: 16 December 2018

\begin{abstract}
Intramolecular photocyclization of stilbene derivatives (Mallory reaction) is one of the efficient methods for building polycyclic aromatic hydrocarbon (PAH) frameworks, and is also expected to be applicable to synthesis of fluorine-containing PAHs (F-PAHs). In this study, dibenzoanthracene-type (4a) and benzoperylene-type (4b) F-PAHs were synthesized using the Mallory reaction of the 1,4-distyrylbenzene-type $\pi$-conjugated molecule (3a), which was prepared by addition-defluorination of available octafluorocyclopentene (OFCP) and aryllithium in three steps. The structure of $\mathbf{4 a}$ originating from $\pi-\pi$ interaction was characterized by X-ray crystallographic analysis. The absorption maxima of UV-Vis spectra and emission maxima of photoluminescence spectra of the PAHs were positioned at a longer wavelength compared to those of the corresponding unsubstituted PAHs, presumably due to the electron-withdrawing nature of perfluorocyclopentene (PFCP) units. The effect of PFCP units in F-PAHs was also studied by time-dependent density functional theory (TD-DFT) calculation.
\end{abstract}

Keywords: polycyclic aromatic hydrocarbons; dibenzoanthracene; benzoperylene; $\pi$-conjugated molecules; Mallory reaction; addition-defluorination; octafluorocyclopentene

\section{Introduction}

Fluorine-containing polycyclic aromatic hydrocarbons (F-PAHs) [1] have attracted much attention in the field of material chemistry as n-type semiconductors for fabrication of electronic and optical devices [2]. In order to synthesize F-PAHs in short steps, it is inevitable to introduce fluorine or organofluorine groups into the PAH framework. Direct fluorination of PAH with a fluorinated reagent [3,4] is a typical and simple synthetic method, however it requires expensive $\mathrm{XeF}_{2}$ [3] or treatment of a fluorinated reagent (e.g., $N$-fluoro-2,4-dinitroimidazole) using $\mathrm{F}_{2}$ gas [4]. Furthermore, this method usually yields a mixture of regioisomers of F-PAHs, due to the difficulty of selective 
fluorination to the mother PAH skeleton, except for a few cases [5,6]. On the other hand, the ring-closing process of fluorine-containing aromatic compounds can basically achieve the desired regiospecific F-PAH. For example, Ichikawa and his coworkers reported metal-catalyzed Friedel-Crafts-type intramolecular cyclization of difluoroalkene and the nearest phenyl unit [7-9]. In this case, fluorine was pinpoint introduced to a phenacene skeleton. Kikuzawa and his groups developed a synthesis of hexafluoro-hexa-peri-hexabenzocoronene, which showed an n-type character in a fabricated FET (field effect transistor) device, using chemical oxidative intramolecular cyclization (Scholl reaction) of the corresponding hexaphenylbenzene [10].

The Mallory reaction is a useful intramolecular photocyclization of stilbene derivatives for synthesis of phenanthrenes via cis-trans isomerization [11-13], which is also applicable to the formation of F-PAHs. In recent years, regiospecific F-PAHs have been synthesized by photocyclization of 1,2-diarylfluoroalkenes via Julia-Kocienski olefination [14] or the Wittig reaction [15]. Our group also reported fluorine-containing phenanthrenes [16] using the Mallory reaction of the corresponding stilbene-type precursor, which were obtained by the reaction of available octafluorocyclopentene (OFCP) with two equivalents of aryllithium under milder conditions (addition-defluorination [17]). The merit of addition-defluorination toward fluorine-containing alkene is the stepwise introduction of two different aromatic rings to give an asymmetric diarylethene in only two steps. Therefore, a combination of the Mallory reaction and addition-defluorination has the ability to supply a wide variety of F-PAHs containing perfluorocyclopentene (PFCP) unit(s).

Herein, we report the synthesis of 1,4-distyrylbenzene-like $\pi$-conjugated molecule bearing PFCP units by reaction of available OFCP with aryllithium derivatives. We also describe fluorine-containing dibenzoanthracene and benzoperylene using the sequential Mallory reaction of the synthesized precursor.

\section{Results}

\subsection{Synthesis of Fluorine-Containing Dibenzoanthracene (4a) and Benzoperylene (4b)}

The synthetic route to fluorine-containing dibenzoanthracene $4 \mathrm{a}$ and benzoperylene $4 \mathbf{b}$ is shown in Scheme 1. Preparation of 1-phenyl-heptafluorocyclopentene 1 (64\%, literature 29\% [17]) was carried out by reaction of OFCP and 1 equiv. of phenylmagnesium bromide, according to the literature [17]. Treatment of $\mathbf{1}$ with 4-bromophenyllithium in THF gave unsymmetric diarylethene $\mathbf{2}$ as a colorless oil in 52\% yield. Lithiated 2 , generated from 2 and ${ }^{n} \mathrm{BuLi}$, was reacted with $\mathbf{1}$ in THF to afford the precursor for the following Mallory reaction, giving 3 as white powder in 22\% yield.

Mallory reaction of 3 in benzene was carried out under light irradiation $(\lambda=365 \mathrm{~nm})$ at room temperature (rt) for $3 \mathrm{~h}$ in the presence of iodine (1.6 equiv.) as an oxidant and excess amounts of 1,2-epoxybutane as a scavenger of the formed hydrogen iodide to give the mixture of the ring-closed products $4 \mathbf{a}$ and $\mathbf{4 b}$, confirmed by ${ }^{1} \mathrm{H}-\mathrm{NMR}$ spectroscopy. Benzoperylene-type $4 \mathbf{b}$ in the reaction mixture was sublimed under reduced pressure $(0.1 \mathrm{kPa})$ at $160^{\circ} \mathrm{C}$, however the sublimate still contained a small amount of dibenzoanthracene-type 4a. The sublimate was purified by preparative layer chromatography (PLC) (silica) to afford pure $4 \mathbf{a}$ and $\mathbf{4 b}$ (13\% yield). After removal of the first sublimate, the residue was heated up to $250{ }^{\circ} \mathrm{C}$ under $0.1 \mathrm{kPa}$ to result in sublimation of $4 \mathbf{a}$ ( $22 \%$ as total yield); the low yields were due to loss of the products in repeated purification (PLC and sublimation). Compared to the solubility of $\mathbf{3}$, both $4 \mathbf{a}$ and $\mathbf{4 b}$ have quite low solubility in organic solvents, such as chloroform and dichloromethane. Formation of [5]helicene-type compound was not detected after the Mallory reaction. It is known that photocyclization of 1,4-distyrylbenzene derivatives preferably gives benzoperylene, [5] helicene, or both, whereas photocyclization affords dibenzoanthracene in low yields $[13,18,19]$. The above Mallory reaction of $\mathbf{3}$ indicates that formation of dibenzoanthracene-like structure, and rotation of one of the PFCP units to form benzoperylene-like structure, are competitive as the second photocyclization. It is also supposed that the third photocyclization spontaneously occurred to give benzoperylene-like $4 \mathrm{~b}$ once the second photocyclization proceeded in [5]helicene-type form. 


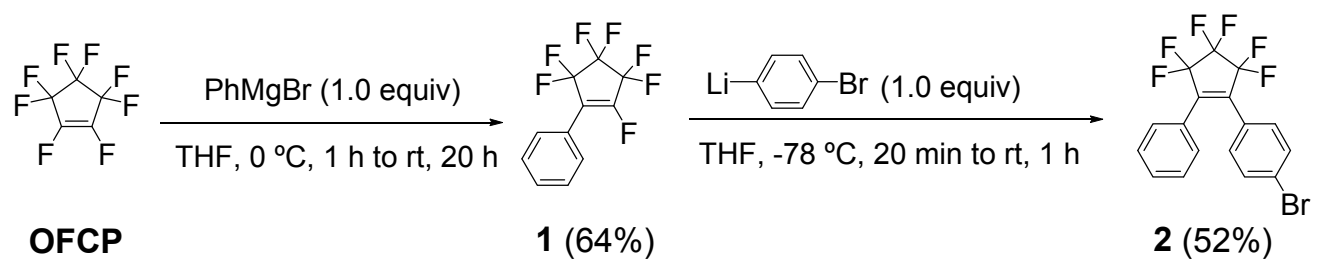

1) ${ }^{n} \mathrm{BuLi}$ (1.0 equiv), THF, $-78^{\circ} \mathrm{C}, 30 \mathrm{~min}$

2) 1 (1.0 equiv), THF, $-78^{\circ} \mathrm{C}, 1 \mathrm{~h}$ to rt, $1 \mathrm{~h}$

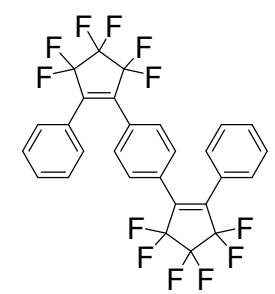

$3(22 \%)$

$\mathrm{I}_{2}$ (1.6 equiv), 1,2-epoxybutane (excess) $\mathrm{h} v$, benzene, $\mathrm{rt}, 3 \mathrm{~h}$

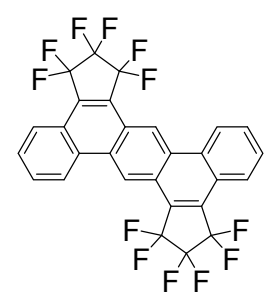

4a $(22 \%)$

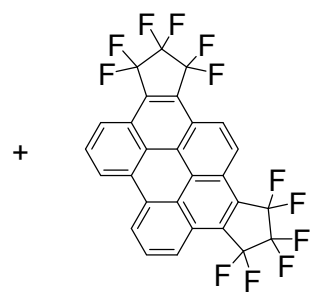

4b $(13 \%)$

Scheme 1. Synthetic route to fluorine-containing $\mathbf{4 a}$ and $\mathbf{4 b}$.

${ }^{1} \mathrm{H}-\mathrm{NMR}$ spectra of $\mathbf{3}, \mathbf{4 a}$, and $\mathbf{4 b}$ are depicted in the Supporting Information. In the spectrum of 3 (Figure S4), signals of two terminal phenyl and central phenylene protons are observed in the typical aromatic region. For spectra of $\mathbf{4 a}$ and $\mathbf{4 b}$ (Figures S7 and S9), all the peaks clearly appear at a lower magnetic field than those observed in that of 3 , owing to the magnetic deshielding effect of the extended $\pi$-conjugated PAH framework. In particular, the singlet observed at $9.77 \mathrm{ppm}$ in the spectrum of $4 \mathbf{a}$ is assignable to the protons bound to the carbons of the central ring in the dibenzoanthracene framework, due to the induced effect originating from the neighborhood fluorines in the PFCP units.

\subsection{Molecular Structures of $\mathbf{3}, \mathbf{4 a}$, and $\mathbf{4} \mathbf{b}$}

The molecular structures of $\mathbf{3}, \mathbf{4 a}$, and $\mathbf{4 b}$ revealed by $\mathrm{X}$-ray crystallographic study are shown in Figure 1. The structures of precursor 3 and dibenzoanthracene 4 a have four and two independent molecules in the unit cell, respectively. One of the independent molecules (molecule A for $\mathbf{3}$ in Figure 1a and molecule E for $\mathbf{4 a}$ in Figure 1b) is depicted in Figure 1 for clarity. Benzoperylene $\mathbf{4 b}$ (Figure 1c) and 3 (molecules $C$ and D in Figure 1a) show disorder in fluorine atoms. Precursor 3 takes a flexible backbone with dihedral angle between the central phenylene plane $\left(\mathrm{C} 3-\mathrm{C} 8-\mathrm{C} 21-\mathrm{C} 3^{*}-\mathrm{C} 8^{*}-\mathrm{C} 21^{*}\right)$ and the terminal phenyl plane (C25-C34-C44-C49-C45-C33) of $60.2^{\circ}$, to result in no face-to-face $\pi-\pi$ interactions between neighborhood molecules (Figure 1a). The $C=C$ bond distance between $C 5$ and C12 in the five-membered unit is 1.353(5) $\AA$ (molecule A), which is comparable to the reported similar diarylethene derivatives [20]. For 4a, two independent molecules (molecules $\mathrm{E}$ and F) are herringbone-like packed in the unit cell, and one of two independent molecules (molecule E) partly overlaps to make a pair with terminal naphthalene units (C2-C3-C4-C5-C8-C9-C10-C11-C6-C7) in the neighboring molecule; the distance between the centroids in the dibenzoanthracene skeleton is $7.15 \AA$. The distance between dibenzoanthracene planes is $3.55 \AA$, due to the $\pi-\pi$ interaction (Figure $1 \mathrm{~b}$ ). The shortest intermolecular fluorine-fluorine (F2-F5) distance between the pairing molecules is ca. $2.67 \AA$, which is shorter than the sum of the van der Waals radius $(2.94 \AA)$, indicating that not only the $\pi-\pi$ interaction, but also the F-F interaction partly contribute to the packing of the molecules of 4a [21]. The length of the $C=C$ bond $(C(3)-C(4))$ fused with the perfluorocycloalkane unit is 1.354(5) $\AA$. In the 
case of $\mathbf{4 b}$, the molecules construct a columnar structure extended to a axis in the crystal (Figure 1c). In sharp contrast to the case of $\mathbf{4 a}$, the nearest two molecules of $\mathbf{4 b}$ fully overlap where possible, to avoid steric repulsion between the bulky PFCP units, Such overlap of benzoperilene skeletons is observed in unsubstituted benzoperylene [22] and 1,2-disubstituted benzoperylene [23].
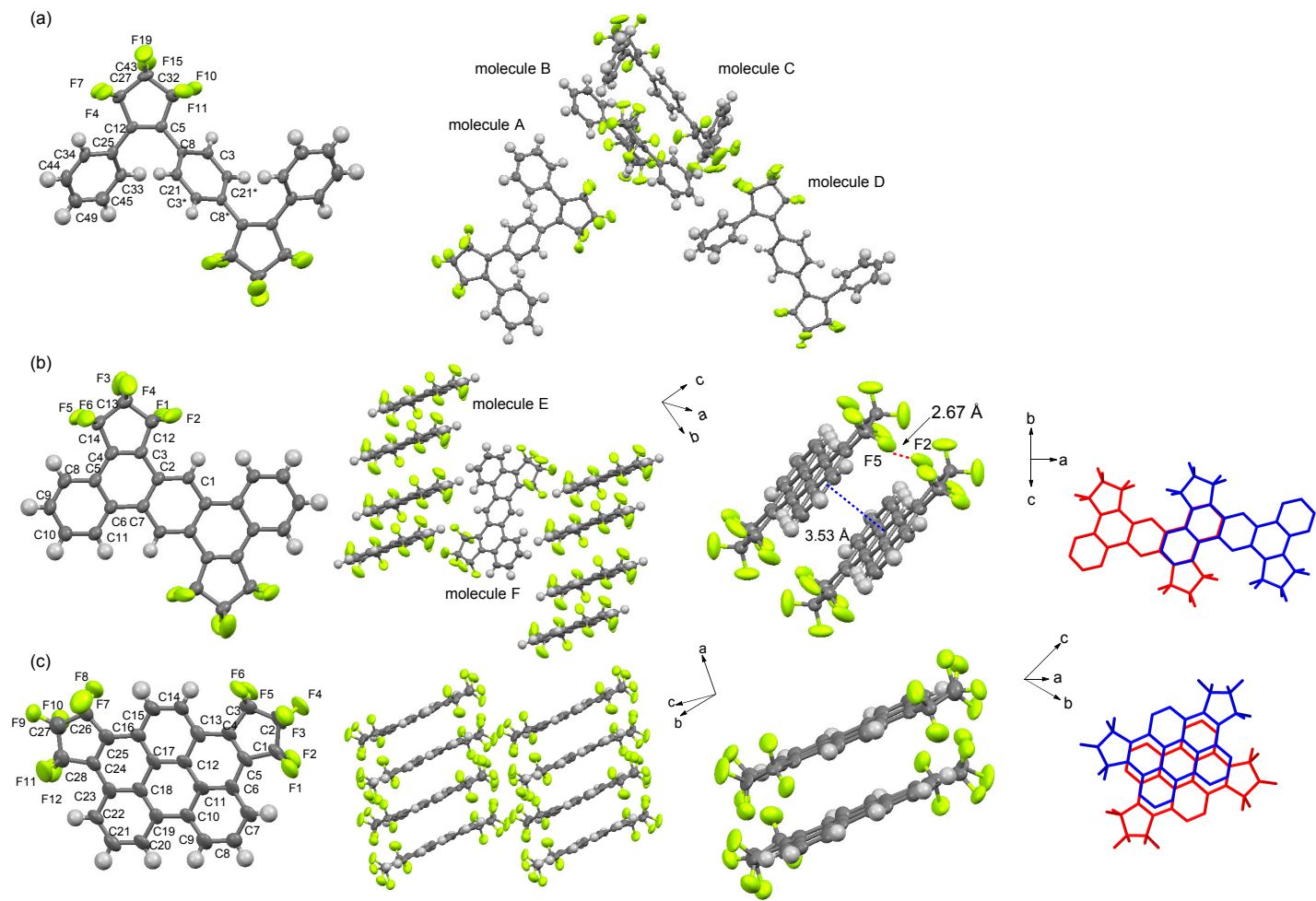

Figure 1. Molecular structures and packing modes of (a) 3, (b) 4a, and (c) $4 b$. One of the independent molecules (3: molecule A, 4a: molecule E) is shown for clarity. Two fluorine atoms (F9 and F10) bound to $\mathrm{CF}_{2}$ carbon (C27) in $\mathbf{4 b}$ and some fluorine atoms in two independent molecules (molecules $\mathrm{C}$ and $\mathrm{D}$ ) of 3 are disordered (see Figures S13 and S15). For 4a, the face-to-face distance is calculated between the polyaromatic hydrocarbon (PAH) cores, which are optimized by the least square method. For $\mathbf{4 b}$, its crystallographic data are not satisfied to discuss the bond lengths and short-contacts distances (see Section 3.5).

\subsection{UV-Vis and Photoluminescence Spectra of $\mathbf{3}, \mathbf{4 a}$, and $\mathbf{4} \mathbf{b}$}

UV-Vis and photoluminescence (PL) spectra of $\mathbf{4 a}$ and $\mathbf{4 b}$ are shown in Figure $2 \mathrm{a}, \mathrm{b}$, respectively, and the optical data are summarized in Table 1. For comparison, UV-Vis and PL spectra of the corresponding precursor 3 were also measured, as depicted in Figure S12. The absorption maximum $\left(\lambda_{\max }\right)$ in the spectrum of 3 appears at $262 \mathrm{~nm}$, due to localization of $\pi$-electrons along the flexible backbone of 3 . In contrast, the spectra of $4 \mathbf{a}$ and $4 \mathbf{b}$ in $\mathrm{CH}_{2} \mathrm{Cl}_{2}$ exhibit $\lambda_{\max }$ at $301 \mathrm{~nm}$ and $309 \mathrm{~nm}$, respectively. This longer wavelength shift presumably originates from extension of the $\pi$-conjugated system on the molecules of $\mathbf{4 a}$ and $\mathbf{4 b}$. The spectrum of dibenzoanthracene $\mathbf{4 a}$ exhibits three medium peaks $\left(\varepsilon=\right.$ ca. $\left.10,000 \mathrm{M}^{-1} \cdot \mathrm{cm}^{-1}\right)$ at 322,336 , and $352 \mathrm{~nm}$, and two small peaks $\left(\varepsilon=\mathrm{ca} .1000 \mathrm{M}^{-1} \cdot \mathrm{cm}^{-1}\right)$ around $390 \mathrm{~nm}$, as comparable to those observed in unsubstituted dibenzoanthracene [24]. On the other hand, the spectrum of benzoperylene $4 \mathrm{~b}$ gives two clear peaks $\left(\varepsilon=\mathrm{ca} .7000 \mathrm{M}^{-1} \cdot \mathrm{cm}^{-1}\right)$ around 380 and $400 \mathrm{~nm}$, which is similar to those of the reported analogues [23]. Time-dependent density functional theory (TD-DFT) calculation supports assignments of absorption peaks in the UV-Vis spectrum of organic molecules. The TD-DFT calculation was carried out at the B3LYP/6-311G(d) level, and the initial structures of $\mathbf{4 a}$ and $\mathbf{4 b}$ were obtained using their X-ray crystallographic data. The results indicate that the bands that appeared at 401 and $309 \mathrm{~nm}$ in the spectrum of $4 \mathrm{~b}$ correspond to 
the transition from HOMO (the highest occupied molecular orbital) to LUMO (the lowest unoccupied molecular orbital) with oscillator strength (f) of $0.2041\left(\lambda_{\text {calc }}=399 \mathrm{~nm}\right)$, and the HOMO $\rightarrow \mathrm{LUMO}+$ $1\left(\mathrm{f}=0.3049, \lambda_{\text {calc }}=307 \mathrm{~nm}\right)$ transition, respectively (Table S1). The DFT calculation also suggests that the $\mathrm{HOMO} \rightarrow \mathrm{LUMO}+1\left(\mathrm{f}=0.5972, \lambda_{\text {calc }}=305 \mathrm{~nm}\right)$ transition corresponds to the large peak $\left(\varepsilon=64,000 \mathrm{M}^{-1} \cdot \mathrm{cm}^{-1}\right)$ at $301 \mathrm{~nm}$ in the spectrum of $4 \mathrm{a}$, and the weak band $\left(\varepsilon=1120 \mathrm{M}^{-1} \mathrm{~cm}^{-1}\right)$ around $380 \mathrm{~nm}$ is thought to be the $\mathrm{HOMO} \rightarrow$ LUMO transition $\left(\mathrm{f}=0.0146, \lambda_{\text {calc }}=381 \mathrm{~nm}\right)$.

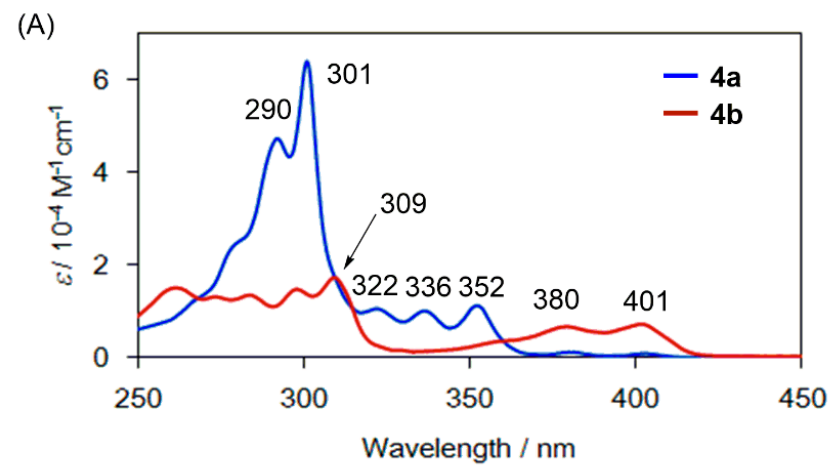

(B)

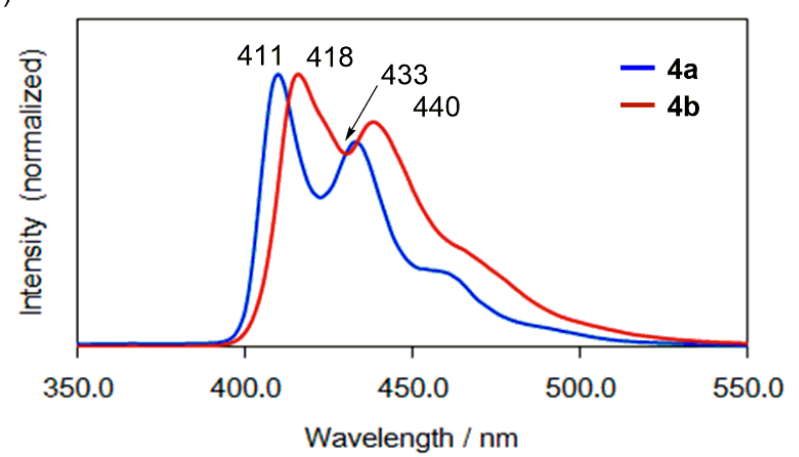

Figure 2. UV-Vis (A) and photoluminescence (B) spectra of $4 \mathbf{a}$ (blue line) and $\mathbf{4 b}$ (red line) in $\mathrm{CH}_{2} \mathrm{Cl}_{2}$.

Table 1. UV-Vis and photoluminescence spectral data of $4 \mathbf{a}$ and $4 \mathbf{b}^{\mathrm{a}}$.

\begin{tabular}{ccc}
\hline F-PAH & $\mathbf{U V - V i s}{ }^{a} \boldsymbol{\lambda}_{\text {max }}, \mathbf{n m}\left(\varepsilon, \mathbf{M}^{-\mathbf{1}} \mathbf{c m}^{-\mathbf{1}}\right)$ & Photoluminescence $\boldsymbol{\lambda}_{\mathrm{em}}, \mathbf{n m}$ \\
\hline 4a & $292(47000), 301(64000), 322(10400), 336$ & 411,433 \\
& $(10000), 352(11000), 380(1120), 401(750)$ & 418,440 \\
4b & $284(13400), 298(14600), 309(17600), 379$ & \\
& $(6600), 401(7100)$ & \\
\hline
\end{tabular}

${ }^{\mathrm{a}}$ Measured in $\mathrm{CH}_{2} \mathrm{Cl}_{2} \cdot{ }^{\mathrm{b}}[\mathbf{4 a}]=1.6 \times 10^{-5} \mathrm{M}$ and $[\mathbf{4 b}]=3.1 \times 10^{-5} \mathrm{M}$.

The Mallory reaction products are photoluminescent in $\mathrm{CH}_{2} \mathrm{Cl}_{2}$ (Figure 2b). The main PL peaks

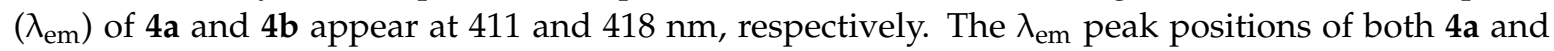
$4 \mathrm{~b}$ shift to longer wavelengths than those of the corresponding unsubstituted dibenzoanthracene $\left(\lambda_{\mathrm{em}}=398 \mathrm{~nm}\right)$ [24] and benzoperylene $\left(\lambda_{\mathrm{em}}=408 \mathrm{~nm}\right)$ [23], respectively. In recent years, it has been reported that introduction of electron-withdrawing methoxycarbonyl group(s) into the C1 and C2 carbons of benzoperylene causes a longer wavelength shift of their PL spectra [23]. In the case of $\mathbf{4 b}$, PFCP units may contribute to the red-shift of the $\lambda_{\text {em }}$ peak, although the PFCP units are fused on the $\mathrm{C} 3, \mathrm{C} 4, \mathrm{C} 11$, and C12 carbons of $\mathbf{4 b}$. In contrast, the PL spectrum of precursor 3 exhibited a very weak band at approximately $430 \mathrm{~nm}$ in $\mathrm{CHCl}_{3}$ (Figure S12), due to the small effective $\pi$-conjugation length along the distorted molecule of 3 . 


\subsection{Computational Study}

To evaluate effect of the introduction of PFCP units to the PAH backbone, a computational study was carried out by DFT at the B3LYP /6-311G(d) level, together with $\mathbf{4 a -}-\mathbf{H}^{*}$ and $\mathbf{4} \mathbf{b}-\mathbf{H}^{*}$, in which all the fluorine atoms of $\mathbf{4 a}$ and $\mathbf{4} \mathbf{b}$ are replaced with hydrogen atoms for comparison (Figure 3). As shown in this diagram, the LUMOs in $\mathbf{4 a}$ and $\mathbf{4 b}$ are extended to the PFCP units, and their LUMO levels $(-2.96 \mathrm{eV}$ for $\mathbf{4} \mathbf{a}$ and $-3.12 \mathrm{eV}$ for $\mathbf{4 b})$ are remarkably lower than those of $\mathbf{4 a}-\mathbf{H}^{*}(-1.60 \mathrm{eV})$ and $\mathbf{4 b}-\mathbf{H}^{*}(-1.77 \mathrm{eV})$. The HOMO levels of $4 \mathbf{a}(-6.75 \mathrm{eV})$ and $4 \mathbf{b}(-6.57 \mathrm{eV})$ are also lower than those of $4 \mathbf{a}-\mathbf{H}^{*}(-5.36 \mathrm{eV})$ and $4 \mathbf{b}-\mathrm{H}^{*}(-5.22 \mathrm{eV})$, due to electro-negative fluorine groups in PFCP units. The HOMO-LUMO gap of benzoperylene-type $4 \mathbf{b}(3.45 \mathrm{eV})$ is smaller than that of dibenzoanthracene-type $4 \mathbf{a}(3.79 \mathrm{eV})$. This trend is consistent with the difference in the UV-Vis absorption peaks between $\mathbf{4 a}$ and $\mathbf{4 b}$, as described above.

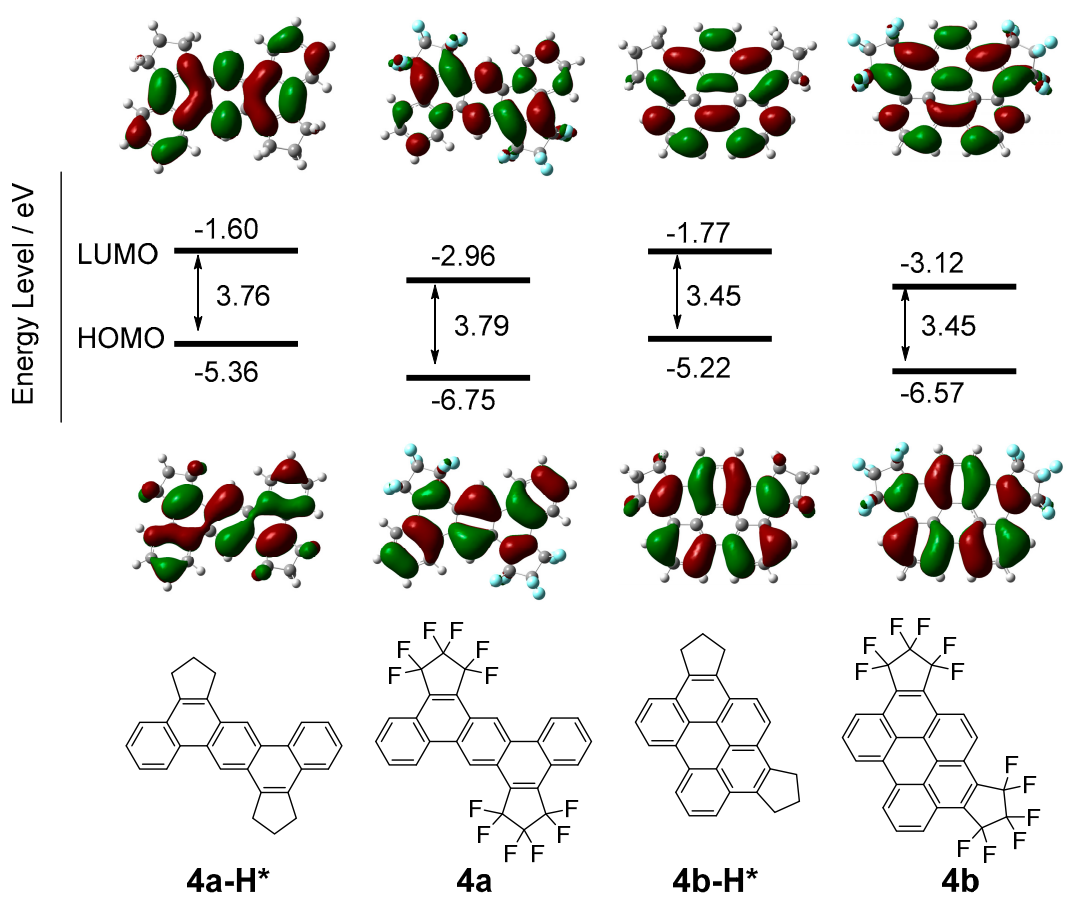

Figure 3. Molecular orbital diagram for fluorine-containing PAHs (F-PAHs) (4a and $\mathbf{4 b}$ ) and their corresponding PAH $\left(\mathbf{4 a}-\mathbf{H}^{*}\right.$ and $\left.\mathbf{4 b}-\mathbf{H}^{*}\right)$, in which all fluorine atoms in $\mathbf{4 a}$ and $\mathbf{4 b}$ are replaced with hydrogen atoms.

\section{Materials and Methods}

\subsection{General}

All manipulations were conducted by standard Schlenk techniques in argon atmosphere. ${ }^{1} \mathrm{H}-,{ }^{13} \mathrm{C}-$, and ${ }^{19} \mathrm{~F}-\mathrm{NMR}$ spectra were measured with a Bruker AVANCE III 400 spectrometer $\left({ }^{1} \mathrm{H}-\mathrm{NMR}\right.$ : $400 \mathrm{MHz},{ }^{19} \mathrm{~F}-\mathrm{NMR}$ : $376 \mathrm{MHz},{ }^{13} \mathrm{C}-\mathrm{NMR}$ : $100 \mathrm{MHz}$; Bruker Corporation, Billerica, MA, USA). $\mathrm{SiMe}_{4}$ was used as an internal standard for ${ }^{1} \mathrm{H}$ - and ${ }^{13} \mathrm{C}-\mathrm{NMR}$ spectra, and $\mathrm{CFCl}_{3}$ was adopted as an external standard for ${ }^{19} \mathrm{~F}-\mathrm{NMR}$ spectra. UV-Vis and photoluminescence spectra were recorded on a Shimadzu UV-3100PC spectrometer (Shimadzu Corporation, Kyoto, Japan) and a Hitachi F-4500 spectrometer (Hitachi High-Technologies Corporation, Tokyo, Japan), respectively. Elemental analysis was carried out using a J-Science Lab JM10 microanalyzer (J-Science Lab Co., Ltd., Kyoto, Japan). High resolution mass spectra (HRMS) were taken using a JEOL JMS-700 analyzer (JEOL Ltd., Akishima, Japan). Mallory reaction of $\mathbf{3}$ was conducted using a USHIO Optical Modulex Multi-purpose lighting unit (irradiation wavelength $=365 \mathrm{~nm}$, light power $=20 \mathrm{~mW} / \mathrm{cm}^{2}$; USHIO INC., Tokyo, Japan). Octafluorocyclopentene (OFCP) was purchased and used without further purification. 1-Phenyl-heptafluorocyclopentene (1) was prepared according to the literature [17]. 


\subsection{Synthesis of 1-(4-bromophenyl)-2-phenyl-3,3,4,4,5,5-hexafluorocyclopentene (2)}

To a THF $(10 \mathrm{~mL})$ solution of 1,4-dibromobenzene $(0.71 \mathrm{~g}, 3.0 \mathrm{mmol}),{ }^{\mathrm{n}} \mathrm{BuLi}(1.6 \mathrm{M}$ hexane solution, $1.9 \mathrm{~mL}, 3.0 \mathrm{mmol})$ at $-78{ }^{\circ} \mathrm{C}$ was added, and the reaction temperature was kept at $-78{ }^{\circ} \mathrm{C}$ for $20 \mathrm{~min}$. $\mathbf{1}(0.81 \mathrm{~g}, 3 \mathrm{mmol})$ was added to the reaction mixture at $-78{ }^{\circ} \mathrm{C}$, then the reaction temperature was raised up to $\mathrm{rt}$ for $1 \mathrm{~h}$. The reaction mixture was poured into saturated $\mathrm{NH}_{4} \mathrm{Cl}$ aqueous solution (ca. $10 \mathrm{~mL}$ ) and extracted with ethyl acetate (ca. $60 \mathrm{~mL}$ ). The organic layer was washed with distilled water and dried over $\mathrm{MgSO}_{4}$. The solvent was removed at reduced pressure, and the resulting residue was purified by column chromatography on silica (eluent = hexane) to afford 2 as a colorless oil ( $0.63 \mathrm{~g}$, 52\%). ${ }^{1} \mathrm{H}-\mathrm{NMR}\left(400 \mathrm{MHz}, \mathrm{CDCl}_{3}\right): \delta 7.50-7.55(\mathrm{~m}, 2 \mathrm{H}), 7.44-7.30(\mathrm{~m}, 5 \mathrm{H}), 7.20(\mathrm{~d}, J=8.8 \mathrm{~Hz}, 2 \mathrm{H})$. ${ }^{13} \mathrm{C}\left\{{ }^{1} \mathrm{H}\right\}-N M R\left(100 \mathrm{MHz}, \mathrm{CDCl}_{3}\right): \delta 140.26(\mathrm{~m}), 138.50(\mathrm{~m}), 132.26,130.84,130.54,129.21,129.06,127.46$, $126.66,125.04,116.33$ (triplet of triplets (tt), $J=255.7$ and $23.9 \mathrm{~Hz}), 111.07(\mathrm{tt}, J=269.7$ and $25.0 \mathrm{~Hz}$ ). The central $\mathrm{CF}_{2}$ carbon in the five-membered ring was not clearly observed, presumably because the intensity of the peak with multicity became very weak. ${ }^{19} \mathrm{~F}-\mathrm{NMR}\left(376 \mathrm{MHz}, \mathrm{CDCl}_{3}\right): \delta-110.38(\mathrm{~m}, 2 \mathrm{~F})$, $-110.60(\mathrm{~m}, 2 \mathrm{~F}),-131.66(\mathrm{~m}, 2 \mathrm{~F})$. HRMS (FAB positive, $m / z)$ : Found, 406.9868; calcd. for $\mathrm{C}_{17} \mathrm{H}_{10} \mathrm{BrF}_{6}$ $\left([\mathrm{M}+\mathrm{H}]^{+}\right), 406.9825$.

\subsection{Synthesis of 1,1'-[1,4-phenylenebis(3,3,4,4,5,5-hexafluorocyclopent-1-ene-2,1-diyl)]dibenzene (3)}

To a THF (5 mL) solution of $2(0.63 \mathrm{~g}, 1.5 \mathrm{mmol}),{ }^{\mathrm{n}} \mathrm{BuLi}(1.6 \mathrm{M}$ hexane solution, $0.9 \mathrm{~mL}, 1.5 \mathrm{mmol})$ at $-78{ }^{\circ} \mathrm{C}$ was added, and the reaction temperature was kept at $-78{ }^{\circ} \mathrm{C}$ for $30 \mathrm{~min}$. After consumption of $2,1(0.41 \mathrm{~g}, 1.5 \mathrm{mmol})$ was added to the reaction mixture at $-78^{\circ} \mathrm{C}$. The reaction temperature was kept at $-78{ }^{\circ} \mathrm{C}$ for $1 \mathrm{~h}$, and then raised up to $\mathrm{rt}$ for $1 \mathrm{~h}$. The reaction mixture was poured into saturated $\mathrm{NH}_{4} \mathrm{Cl}$ aqueous solution (ca. $5 \mathrm{~mL}$ ) and extracted with ethyl acetate (ca. $60 \mathrm{~mL}$ ). The organic layer was washed with distilled water and dried over $\mathrm{MgSO}_{4}$. The solvent was removed at reduced pressure, and the resulting residue was purified by column chromatography on silica (eluent = hexane) to give 3 as white powder $(0.19 \mathrm{~g}, 22 \%) .{ }^{1} \mathrm{H}-\mathrm{NMR}\left(400 \mathrm{MHz},\left(\mathrm{CD}_{3}\right)_{2} \mathrm{CO}\right): \delta 7.58-7.45(\mathrm{~m}, 10 \mathrm{H}), 7.43(\mathrm{~d}, \mathrm{~J}=7.6 \mathrm{~Hz}$, $4 \mathrm{H}) .{ }^{13} \mathrm{C}\left\{{ }^{1} \mathrm{H}\right\}-\mathrm{NMR}\left(100 \mathrm{MHz},\left(\mathrm{CD}_{3}\right)_{2} \mathrm{CO}\right): \delta 141.33(\mathrm{~m}), 138.87(\mathrm{~m}), 130.83,130.00,129.63,129.24,129.08$, $127.04,116.42(\mathrm{tt}, J=256.4$ and $21.8 \mathrm{~Hz}), 111.29(\mathrm{tt}, J=269.6$ and $24.9 \mathrm{~Hz})$. The central $\mathrm{CF}_{2}$ carbon in the five-membered ring was not clearly observed, presumably because the intensity of the peak with multicity became very weak. ${ }^{19} \mathrm{~F}-\mathrm{NMR}\left(376 \mathrm{MHz},\left(\mathrm{CD}_{3}\right)_{2} \mathrm{CO}\right): \delta-110.04$ to $-110.07(\mathrm{~m}, 4 \mathrm{~F}),-110.37$ to $-111.41(\mathrm{~m}, 4 \mathrm{~F}),-132.36$ (quint, $J=4.5 \mathrm{~Hz}, 4 \mathrm{~F}$ ). Found: $\mathrm{C}, 58.17 ; \mathrm{H}, 2.68$. Calcd. for $\mathrm{C}_{28} \mathrm{H}_{14} \mathrm{~F}_{12}: \mathrm{C}_{\text {, }}$ $58.14 ; \mathrm{H}, 2.44$.

3.4. Synthesis of 1,1,2,2,3,3,9,9,10,10,11,11-dodecafluoro-1,2,3,9,10,11hexahydrobenzo[k]dicyclopentalf,m] tetraphene (4a) and 1,1,2,2,3,3,10,10,11,11,12,12-dodecafluoro1,2,3,10,11,12-hexahydrobenzo[pqr]dicyclopenta[b,n]perylene $(\mathbf{4 b})$

To a mixture of $3(0.042 \mathrm{~g}, 0.073 \mathrm{mmol})$ and benzene $(30 \mathrm{~mL})$, iodine $(0.029 \mathrm{~g}, 0.12 \mathrm{mmol})$ at $\mathrm{rt}$ was added in Ar atmosphere. After stirring for $30 \mathrm{~min}, 1,2$-epoxybutane $(0.3 \mathrm{~mL}, 3.5 \mathrm{mmol})$ was added to the mixture, which was stirred under light irradiation at $\mathrm{rt}$ for $3 \mathrm{~h}$. The reaction mixture was poured into saturated sodium thiosulfate aqueous solution $(10 \mathrm{~mL})$, and the resulting organic layer was washed with distilled water $(10 \mathrm{~mL})$ and brine $(10 \mathrm{~mL})$. After separation and drying of the layer, the solvent was evaporated at reduced pressure. The resulting residue was heated under $0.1 \mathrm{kPa}$ at $160{ }^{\circ} \mathrm{C}$, and the sublimate was separated by column chromatography on silica (eluent: ethyl acetate/hexane $=1 / 4$ ) to afford $4 \mathbf{a}$ and $\mathbf{4 b}$. The residue after the first sublimation was heated again under $0.1 \mathrm{kPa}$ at 250 ${ }^{\circ} \mathrm{C}$ to sublime 4a. 4a-colorless powder $(10 \mathrm{mg}, 22 \%) .{ }^{1} \mathrm{H}-\mathrm{NMR}\left(400 \mathrm{MHz}, \mathrm{CDCl}_{3}\right): \delta 9.77(\mathrm{~s}, 2 \mathrm{H})$, $9.01(\mathrm{~d}, J=8.0 \mathrm{~Hz}, 2 \mathrm{H}), 8.49(\mathrm{~d}, J=7.2 \mathrm{~Hz}, 2 \mathrm{H}), 8.07(\mathrm{t}, J=7.2 \mathrm{~Hz}, 2 \mathrm{H}), 7.93(\mathrm{t}, J=8.0 \mathrm{~Hz}, 2 \mathrm{H}) .{ }^{19} \mathrm{~F}-\mathrm{NMR}$ $\left(376 \mathrm{MHz} \mathrm{CDCl}_{3}\right): \delta-105.45(\mathrm{~m}, 4 \mathrm{~F}),-106.06(\mathrm{~m}, 4 \mathrm{~F}),-128.75$ (quint, $\left.J=3.8 \mathrm{~Hz}, 4 \mathrm{~F}\right)$. HRMS (FAB positive, $m / z)$ : Found, 574.0552; Calcd. for $\mathrm{C}_{28} \mathrm{H}_{10} \mathrm{~F}_{12}\left([\mathrm{M}]^{+}\right), 574.0591$. $4 \mathrm{~b}$-colorless powder $(6 \mathrm{mg}$, 13\%). ${ }^{1} \mathrm{H}-\mathrm{NMR}\left(400 \mathrm{MHz}, \mathrm{CDCl}_{3}\right): \delta 9.34(\mathrm{~d}, J=8.0 \mathrm{~Hz}, 2 \mathrm{H}), 9.05(\mathrm{~s}, 2 \mathrm{H}), 8.83(\mathrm{~d}, J=8.0 \mathrm{~Hz}, 2 \mathrm{H})$, $8.35(\mathrm{t}, J=8.0 \mathrm{~Hz}, 2 \mathrm{H}) .{ }^{19} \mathrm{~F}-\mathrm{NMR}\left(376 \mathrm{MHz}, \mathrm{CDCl}_{3}\right): \delta-105.61(\mathrm{~m}, 4 \mathrm{~F}),-106.17(\mathrm{~m}, 4 \mathrm{~F}),-128.7$ $(\mathrm{t}, J=3.8 \mathrm{~Hz}, 4 \mathrm{~F})$. HRMS (FAB positive, $m / z)$ : Found, 572.0458; Calcd. for $\mathrm{C}_{28} \mathrm{H}_{8} \mathrm{~F}_{12}\left([\mathrm{M}]^{+}\right), 572.0434$. 


\subsection{X-Ray Crystallographic Analysis of $\mathbf{3}, \mathbf{4 a}$, and $\mathbf{4 b}$}

Single crystals of $3, \mathbf{4 a}$, and $\mathbf{4 b}$ suitable for $\mathrm{X}$-ray crystallographic analysis were obtained by slow evaporation of the saturated $\mathrm{CH}_{2} \mathrm{Cl}_{2}$ (for $4 \mathbf{a}$ and $\mathbf{4 b}$ ) or hexane (for 3 ) solution at rt. The crystals were mounted on a Rigaku XtaLabMini diffractometer (Rigaku Corporation, Akishima, Japan) using Mo $\mathrm{K} \alpha$ radiation $(\lambda=0.71073 \AA)$. Processing of the collected reflection data was carried out using the CrysAlisPro program (version 1.171.38.46, Rigaku Corporation, Akishima, Japan) [25]. The structure was solved by a direct method (SHELXT-2014/5) and refined by the full-matrix least square method on $\mathrm{F}^{2}$ for all reflections (SHELXTL-2014/7) [26]. All hydrogen atoms were placed using AFIX instructions, and all the other atoms were refined anisotropically. Precursor 3 and benzoperylene $4 \mathrm{~b}$ showed disorder in fluorine atoms (F25, F26, F27, F28, in 3; F9 and F10 in 4b). Dibenzoanthracene 4a and 3 have two and four independent molecules in the unit cell, respectively. Crystallographic data of 3, 4a, and $\mathbf{4 b}$ are deposited on the system of The Cambridge Crystallographic Data Centre: CCDC-1822475 (for 3), CCDC-1822473 (for 4a), and CCDC-1822474 (for 4b). These crystal data can be obtained free of charge from the center via https:/ / www.ccdc.cam.ac.uk/structures/.

Crystal data for 3: $\mathrm{C}_{28} \mathrm{H}_{14} \mathrm{~F}_{12}$, FW 578.39, $-100{ }^{\circ} \mathrm{C}, 0.130 \times 0.120 \times 0.120 \mathrm{~mm}^{3}$, Triclinic, P-1, $\mathrm{a}=10.1230(5) \AA, \mathrm{b}=13.9273(9) \AA, \mathrm{c}=18.2364(11) \AA, \mathrm{V}=2414.6(3) \AA^{3}, \alpha=70.087(6)^{\circ}, \beta=88.323(5)^{\circ}$, $\gamma=87.402(5)^{\circ}, \mathrm{Z}=4, \mathrm{D}_{\text {calcd }}=1.591 \mathrm{~g} \mathrm{~cm}^{-3}, \mu=0.157 \mathrm{~mm}^{-1}, \mathrm{~F}(000)=1160,2.014^{\circ} \leq \theta \leq 25.500^{\circ}$, reflection collected 21,605, independent reflections $8993\left(R_{\text {int }}=0.0373\right)$, completeness to $\theta_{\max } 100.0 \%$, data/restraints/parameters 8993/48/793, GOF on $\mathrm{F}^{2} 1.027, \mathrm{R}_{1}[\mathrm{I}>2 \sigma(\mathrm{I})]$ 0.0710, $\mathrm{wR}^{2}$ (all data) 0.2046, largest diffraction peak and hole 0.871 and -0.464 e $\AA^{-3}$.

Crystal data for 4a: $\mathrm{C}_{28} \mathrm{H}_{10} \mathrm{~F}_{12}$, FW $574.36,-100^{\circ} \mathrm{C}, 0.230 \times 0.180 \times 0.150 \mathrm{~mm}^{3}$, Triclinic, P-1, $\mathrm{a}=7.1452(7) \AA, \mathrm{b}=9.4617(7) \AA, \mathrm{c}=17.8343(15) \AA, \mathrm{V}=1088.81(18) \AA^{3}, \alpha=79.109(7)^{\circ}, \beta=79.718(8)^{\circ}$, $\gamma=67.831(8)^{\circ}, Z=2, D_{\text {calcd }}=1.752 \mathrm{~g} \mathrm{~cm}^{-3}, \mu=0.174 \mathrm{~mm}^{-1}, \mathrm{~F}(000)=572,2.342^{\circ} \leq \theta \leq 25.492^{\circ}$, reflection collected 9765 , independent reflections $4065\left(R_{\text {int }}=0.0508\right)$, completeness to $\theta_{\max } 99.9 \%$, data/restraints/parameters 4065/0/361, GOF on $F^{2} 1.031, R_{1}[I>2 \sigma(I)] 0.0634, \mathrm{wR}^{2}$ (all data) 0.1985, largest diffraction peak and hole 0.365 and $-0.357 \mathrm{e} \AA^{-3}$.

Crystal data for $4 \mathbf{b}: \mathrm{C}_{28} \mathrm{H}_{8} \mathrm{~F}_{12}$, FW $572.34,-100{ }^{\circ} \mathrm{C}, 0.210 \times 0.080 \times 0.050 \mathrm{~mm}^{3}$, Triclinic, P-1, $\mathrm{a}=7.438(3) \AA, \mathrm{b}=11.078(3) \AA, \mathrm{c}=13.181(3) \AA, \mathrm{V}=1024.6(6) \AA^{3}, \alpha=72.22(3)^{\circ}, \beta=82.50(3)^{\circ}$, $\gamma=89.76(3)^{\circ}, \mathrm{Z}=2, \mathrm{D}_{\text {calcd }}=1.855 \mathrm{~g} \mathrm{~cm}^{-3}, \mu=0.184 \mathrm{~mm}^{-1}, \mathrm{~F}(000)=568,1.638^{\circ} \leq \theta \leq 25.495^{\circ}$, reflection collected 9075, independent reflections $3811\left(R_{\text {int }}=0.1310\right)$, completeness to $\theta_{\max } 100.0 \%$, data/restraints/parameters 3811/54/379, GOF on $\mathrm{F}^{2} 1.058, \mathrm{R}_{1}[\mathrm{I}>2 \sigma(\mathrm{I})]$ 0.1448, $\mathrm{wR}^{2}$ (all data) 0.4404, largest diffraction peak and hole 0.963 and $-0.676 \mathrm{e}^{-3}$. The ratio of observed unique reflection is $45 \%$ and $\mathrm{R}$ value is over $10 \%$. Thus, crystallographic data of $4 \mathbf{b}$ can only be used for molecular structure identification as shown in Figure 1c and as the starting molecule for DFT optimization (Figure 3).

\subsection{Computational Method}

DFT calculations were performed using the Gaussian 16 program package (Gaussian, Inc., Wallingford, CT, USA) [27]. The initial geometry of the structures of $4 \mathbf{a}$ and $4 \mathbf{b}$ using their X-ray crystallographic data was optimized at the B3LYP/6-311G(d) level of theory. The computational time was provided by the Super Computer Laboratory, Institute for Chemical Research, Kyoto University. Frequency calculations confirmed that all the optimized geometries are the equilibrium structures. Excited energies and oscillator strengths were calculated on the optimized structures by the TD-DFT method at the B3LYP/6-311G(d) level. Tables S2, S3, S4, and S5 in the supporting information show Cartesian coordinates of the optimized geometries of $4 \mathbf{a}, 4 \mathbf{a}-\mathbf{H}^{*}, \mathbf{4 b}$, and $\mathbf{4 b}-\mathrm{H}^{*}$, respectively.

\section{Conclusions}

In conclusion, we investigated efficient synthesis of fluorine-containing dibenzoanthracene (4a) and benzoperylene (4b) using Mallory reaction of the corresponding 1,4-distyrylbenzene-type precursor (3), which was prepared using addition-defluorination of available OFCP and aryllithium 
derivatives. The structure of $\mathbf{4 a}$ originating from intermolecular $\pi-\pi$ interactions was characterized by X-ray crystallographic analysis. In the structure of $4 \mathbf{a}$, the F-F interaction between the nearest molecules was observed. UV-Vis spectra of $4 \mathbf{a}$ and $\mathbf{4 b}$ in $\mathrm{CH}_{2} \mathrm{Cl}_{2}$ exhibited $\lambda_{\max }$ at 301 and $309 \mathrm{~nm}$, respectively. The main PL peaks $\left(\lambda_{\mathrm{em}}\right)$ of $\mathbf{4 a}$ and $\mathbf{4 b}$ in $\mathrm{CH}_{2} \mathrm{Cl}_{2}$ appeared at 411 and $418 \mathrm{~nm}$, respectively, which shifted to longer wavelengths compared to those of the corresponding unsubstituted dibenzoanthracene and benzoperylene. The effect of electron-withdrawing PFCP units in $\mathbf{4 a}$ and $\mathbf{4 b}$ skeletons was also evaluated by computational study; TD-DFT calculation of $\mathbf{4 a}$ and $4 \mathbf{b}$ revealed that both HOMO and LUMO levels became lower than those of the corresponding non-fluorinated $\mathbf{4 a -}-\mathrm{H}^{*}$ and $\mathbf{4 b}-\mathrm{H}^{*}$. This finding will contribute to the design of new n-type F-PAHs.

Supplementary Materials: The following are available online. Figure S1. ${ }^{1} \mathrm{H}$ NMR spectrum of 2 in $\mathrm{CDCl}_{3}$. Figure S2. ${ }^{19} \mathrm{~F}$ NMR spectrum of 2 in $\mathrm{CDCl}_{3}$. Figure S3. ${ }^{13} \mathrm{C}$ NMR spectrum of 2 in $\mathrm{CDCl}_{3}$. Figure $\mathrm{S}_{4} .{ }^{1} \mathrm{H}$ NMR spectrum of 3 in $\left(\mathrm{CD}_{3}\right)_{2} \mathrm{CO}$. Figure S5. ${ }^{19} \mathrm{~F}$ NMR spectrum of 3 in $\left(\mathrm{CD}_{3}\right)_{2} \mathrm{CO}$. Figure S6. ${ }^{33} \mathrm{C}$ NMR spectrum of 3 in $\left(\mathrm{CD}_{3}\right)_{2} \mathrm{CO}$. Figure S7. ${ }^{1} \mathrm{H}$ NMR spectrum of $4 \mathbf{a}$ in $\mathrm{CDCl}_{3}$. Figure $\mathrm{S} 8 .{ }^{19} \mathrm{~F}$ NMR spectrum of $4 \mathbf{a}$ in $\mathrm{CDCl}_{3}$. Figure S9. ${ }^{1} \mathrm{H}$ NMR spectrum of $4 \mathbf{b}$ in $\mathrm{CDCl}_{3}$. Figure S10. ${ }^{19} \mathrm{~F}$ NMR spectrum of $4 \mathbf{b}$ in $\mathrm{CDCl}_{3}$. Figure $\mathrm{S} 11 .{ }^{1} \mathrm{H}$ NMR spectrum of the first sublimate after sublimation of the crude product in $\mathrm{CDCl}_{3}$. Figure $\mathrm{S} 12$. UV-vis (A) and photoluminescence (B) spectra of $\mathbf{3}$ in $\mathrm{CHCl}_{3}$. Figure S13. Molecular structures of $\mathbf{3}$. Figure S14. Molecular structures of 4a. Figure S15. Molecular structure of $4 \mathbf{b}$. Table S1. Excited states and oscillator strengths of (a) dibenzoanthracene $4 \mathbf{a}$ and (b). benzoperylene $4 \mathbf{b}$, calculated at B3LYP/6-611G(d) level. Table S2. Cartesian coordinates of the optimized geometry of $4 \mathbf{a}$ (in $\AA$ ). Table S3. Cartesian coordinates of the optimized geometry of $\mathbf{4 a - \mathbf { H } ^ { * }}$ (in $\AA$ ). Table S4. Cartesian coordinates of the optimized geometry of $\mathbf{4 b}$ (in $\AA$ ). Table S5. Cartesian coordinates of the optimized geometry of $4 \mathbf{b}-\mathbf{H}^{*}$ (in $\AA$ ).

Author Contributions: In this study, O.G., T.S., T.K., and H.F. conceived and designed the experiment; the contributions of O.G and T.S. were the synthesis and characterization of basic chemical properties of F-PAHs; T.A. determined the molecular structure of $\mathbf{3}, \mathbf{4 a}$, and $\mathbf{4 b}$ by X-ray crystallographic study; T.Y. (Takashi Yamazaki) and T.K.-T. measured the mass spectra of the compounds. T.Y. (Tomoko Yajima) contributed with research and discussion of recent studies concerned with F-PAHs. The manuscript was written and edited by O. G and H.F.

Funding: This work was partly supported by JSPS KAKENHI (No. 15K05513), the Izumi Science and Technology Foundation (H.F.), the Ibaraki University Priority Research Grants (H.F. and T.A.) and the AGC Research Collaboration Program (Takashi Yamazaki, Tomoko Yajima, and T.K.).

Acknowledgments: The authors thank Kyoko Yamamoto at the Research Center, AGC Inc. for her technical support. The computational time was provided by the Super Computer Laboratory, Institute for Chemical Research, Kyoto University.

Conflicts of Interest: The authors declare no conflict of interest.

\section{References}

1. Sun, H.; Kramer, J.H. Perfluoroalkylated PAH n-type semiconductors: Theory and experiment. In New Fluorinated Carbons: Fundamentals and Applications; Boltalina, O.V., Nakajima, T., Eds.; Elsevier: Amsterdam, The Netherlands, 2017; Volume 1, pp. 155-176.

2. Sakamoto, Y.; Suzuki, T.; Kobayashi, M.; Gao, Y.; Fukai, Y.; Inoue, Y.; Sato, F.; Tokito, S. Perfluoropentacene: High-Performance $\mathrm{p}-\mathrm{n}$ junctions and complementary circuits with pentacene. J. Am. Chem. Soc. 2004, 126, 8138-8140. [CrossRef] [PubMed]

3. Bergmann, E.D.; Selig, H.; Lin, C.H.; Rabinovitz, M.; Agranat, I. Reaction of xenon difluoride with polycyclic aromatic hydrocarbons. fluorination of pyrene. J. Org. Chem. 1975, 40, 3793-3794. [CrossRef]

4. Laali, K.K.; Tanaka, M.; Forohar, F.; Cheng, M.; Fetzer, J.C. Facile one-pot fluorination of polycyclic aromatic hydrocarbons (PAHs) with $\mathrm{N}$-fluoro-2,4-dinitroimidazole; scope and limitation. J. Fluorine Chem. 1998, 91, 185-190. [CrossRef]

5. Lee, H.G.; Milner, P.J.; Buchwald, S.L. Pd-catalyzed nucleophilic fluorination of aryl bromides. J. Am. Chem. Soc. 2014, 136, 3792-3795. [CrossRef] [PubMed]

6. Ohashi, M.; Ishida, N.; Ando, K.; Hashimoto, Y.; Shigaki, A.; Kikushima, K.; Ogoshi, S. Cu(I)-catalyzed pentafluoroethylation of aryl iodides in the presence of tetrafluoroethylene and cesium fluoride: Determining the route to key pentafluoroethyl $\mathrm{Cu}(\mathrm{I})$ intermediate. Chem. Eur. J. 2018, 24, 9794-9798. [CrossRef] [PubMed]

7. Fuchibe, K.; Morikawa, T.; Ueda, R.; Okauchi, T.; Ichikawa, J. Pinpoint-fluorinated phenanthrene synthesis based on C-F bond activation of difluoroalkenes. J. Fluorine Chem. 2015, 179, 106-115. [CrossRef] 
8. Fuchibe, K.; Shigeno, K.; Zhao, N.; Aihara, H.; Akisaka, R.; Morikawa, T.; Fujita, T.; Yamakawa, K.; Shimada, T.; Ichikawa, J. Pinpoint-fluorinated polycyclic aromatic hydrocarbons (F-PAHs): Syntheses of difluorinated subfamily and their properties. J. Fluorine Chem. 2017, 203, 173-184. [CrossRef]

9. Fuchibe, K.; Morikawa, T.; Shigeno, K.; Fujita, T.; Ichikawa, J. Pinpoint-fluorinated phenacenes: New synthesis and solubility enhancement strategies. Org. Lett. 2015, 17, 1126-1129. [CrossRef]

10. Kikuzawa, Y.; Mori, T.; Takeuchi, H. Synthesis of 2,5,8,11,14,17-Hexafluoro-hexa-peri-hexabenzocoronene for n-Type organic field-effect transistors. Org. Lett. 2007, 9, 4817-4820. [CrossRef]

11. Mallory, F.B.; Wood, C.S. Photochemistry of stilbenes. IV. The preparation of substituted phenanthrenes. J. Org. Chem. 1964, 29, 3373-3377.

12. Mallory, F.B.; Wood, C.S.; Gordon, J.T. Photochemistry of stilbenes. III. Some aspects of the mechanism of photocyclization to phenanthrenes. J. Am. Chem. Soc. 1964, 86, 3094-3102. [CrossRef]

13. Jørgensen, K.B. Photochemical oxidative cyclisation of stilbenes and stilbenoids-The Mallory reaction. Molecules 2010, 15, 4334-4358. [CrossRef] [PubMed]

14. Banerjee, S.; Sinha, S.; Pradhan, P.; Caruso, A.; Liebowitz, D.; Parrish, D.; Rossi, M.; Zajc, B. Regiospecifically fluorinated polycyclic aromatic hydrocarbons via julia-kocienski olefination and oxidative photocyclization. Effect of fluorine atom substitution on molecular shape. J. Org. Chem. 2016, 81, 3983-3993. [CrossRef] [PubMed]

15. Bae, S.; Mah, H.; Chaturvedi, S.; Jeknic, T.M.; Baird, W.M.; Katz, A.K.; Carrell, H.L.; Glusker, J.P.; Okazaki, T.; Laali, K.K.; et al. Synthetic, crystallographic, computational, and biological studies of 1,4-difluorobenzo[c]phenanthrene and its metabolites. J. Org. Chem. 2007, 72, 7625-7633. [CrossRef] [PubMed]

16. Fukumoto, H.; Ando, M.; Shiota, T.; Izumiya, H.; Kubota, T. Efficient synthesis of fluorinated phenanthrene monomers using Mallory reaction and their copolymerization. Macromolecules 2017, 50, 865-871. [CrossRef]

17. Yamada, S.; Konno, T.; Ishihara, T.; Yamanaka, H. Reaction of octafluorocyclopentene with various carbon nucleophiles. J. Fluorine Chem. 2005, 126, 125-133. [CrossRef]

18. Ito, N.; Hirose, T.; Matsuda, K. Facile photochemical synthesis of 5,10-disubstituted [5]Helicenes by removing molecular orbital degeneracy. Org. Lett. 2014, 16, 2502-2505. [CrossRef]

19. Blum, J.; Zimmerman, M. Photocyclization of substituted 1,4-distyrylbenzenes to dibenz $[a, h]$ anthracenes. Tetrahedron 1972, 28, 275-280. [CrossRef]

20. Hiroto, S.; Suzuki, K.; Kamiya, H.; Shinokubo, H. Synthetic protocol for diarylethenes through Suzuki-Miyaura coupling. Chem. Commun. 2011, 47, 7149-7151. [CrossRef]

21. Baker, R.J.; Colavita, P.E.; Murphy, D.M.; Platts, J.A.; Wallis, J.D. Fluorine-fluorine interactions in the solid state: An experimental and theoretical study. J. Phys. Chem. A 2012, 116, 1435-1444. [CrossRef]

22. Munakata, M.; Wu, L.P.; Ning, G.L.; Kuroda-Sowa, T.; Maekawa, M.; Suenaga, Y.; Maeno, N. Construction of metal sandwich systems derived from assembly of silver(I) complexes with polycyclic aromatic compounds. J. Am. Chem. Soc. 1999, 121, 4968-4976. [CrossRef]

23. Hirayama, S.; Sakai, H.; Araki, Y.; Tanaka, M.; Imakawa, M.; Wada, T.; Takenobu, T.; Hasobe, T. Systematic control of the excited-state dynamics and carrier-transport properties of functionalized benzo[ghi]perylene and coronene derivatives. Chem. Eur. J. 2014, 20, 9081-9093. [CrossRef] [PubMed]

24. Umeda, R.; Miyake, S.; Nishiyama, Y. Synthesis of dibenz $[a, h]$ anthracenes by Pd-catalyzed intramolecular double-cyclization of (Z,Z)-p-styrylstilbenes. Chem. Lett. 2012, 41, 215-217. [CrossRef]

25. Rigaku Oxford Diffraction. CrysAlisPro. 2015. Available online: https://www.rigaku.com/en/products/ smc/crysalis (accessed on 11 December 2018).

26. Sheldrick, G.M. Crystal structure refinement with SHELXL. Acta Cryst. 2015, C71, 3-8.

27. Frisch, M.J.; Trucks, G.W.; Schlegel, H.B.; Scuseria, G.E.; Robb, M.A.; Cheeseman, J.R.; Scalmani, G.; Barone, V.; Petersson, G.A.; Nakatsuji, H.; et al. Gaussian 16, Revision A.03; Gaussian, Inc.: Wallingford, CT, USA, 2016.

Sample Availability: Not available. 